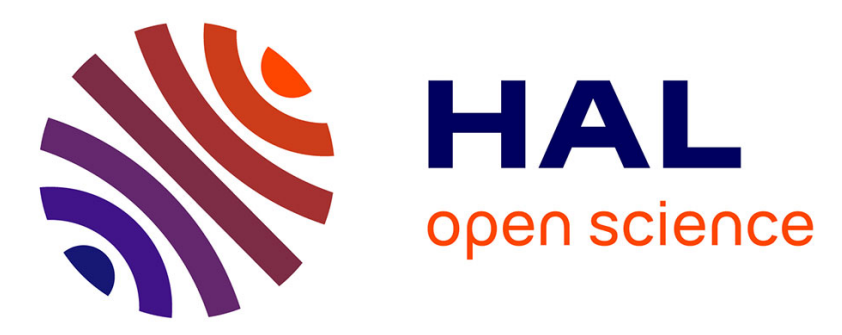

\title{
The electric vehicle: A new driving experience involving specific skills and rules
}

\author{
Elodie Labeye, Myriam Hugot, Corinne Brusque, Michael Regan
}

\section{To cite this version:}

Elodie Labeye, Myriam Hugot, Corinne Brusque, Michael Regan. The electric vehicle: A new driving experience involving specific skills and rules. Transportation Research Part F: Traffic Psychology and Behaviour, 2016, 37, pp.27-40. 10.1016/j.trf.2015.11.008 . hal-01375560v2

\section{HAL Id: hal-01375560 \\ https://hal.science/hal-01375560v2}

Submitted on 11 May 2017

HAL is a multi-disciplinary open access archive for the deposit and dissemination of scientific research documents, whether they are published or not. The documents may come from teaching and research institutions in France or abroad, or from public or private research centers.
L'archive ouverte pluridisciplinaire HAL, est destinée au dépôt et à la diffusion de documents scientifiques de niveau recherche, publiés ou non, émanant des établissements d'enseignement et de recherche français ou étrangers, des laboratoires publics ou privés. 


\title{
The Electric Vehicle: A New Driving Experience
}

\section{Involving specific Skills and Rules}

\author{
Elodie Labeye', Myriam Hugot ${ }^{1}$, Corinne Brusque ${ }^{1}$ \& Michael A. Regan ${ }^{2}$ \\ ${ }^{1}$ Université de Lyon, F-69622, Lyon, France, IFSTTAR, LESCOT, F-69675 Bron \\ ${ }^{2}$ ARRB Group Ltd, Sydney, Australia
}

\begin{abstract}
The arrival of the electric vehicle (EV) on the market is one consequence of government measures to improve air quality and reduce $\mathrm{CO}^{2}$ emissions. However, the $\mathrm{EV}$ has specific properties of use associated with its limited range and relative silence compared to normal vehicles, influencing the mobility behaviours of drivers and requiring them to develop some new driving abilities. This paper examines the behavioural modifications brought about by daily use of an electric vehicle at three different levels of driving activity: strategic, tactical and operational. The study collected and analyzed the self-reported behaviours (via questionnaires and travels dairies) of 36 Parisian private drivers, each of whom drove for six months an electric MINI E prototype. The results of the study show that driving an EV requires a learning phase to acquire the skills and knowledge necessary to operate the vehicle. At the strategic level of driving, drivers take into account the restricted range of the EV, implement a daily charge process, and develop new behaviours related to trip planning. The study also examines driver behaviour at the tactical level, in terms of driver interactions with other road users to deal with the silent nature of the EV, and at the operational level of driving, in terms of braking behaviour to master the regenerative braking function of the EV. The paper discusses the interactions between these three levels of driving activity.
\end{abstract}




\section{Highlights}

Self-reported behaviours engaged in by drivers during daily use of an electric vehicle are reported

Behaviour modifications emerged progressively with time at all driving activity levels

$>$ Driving at the strategic level is enhanced by the establishment of rules in order to optimize range management

At the tactical level adaptive driving behaviours arise to compensate for the lack of vehicle noise

Optimal driving styles arise at the operational level by mastering the regenerative braking function

Dynamic interactions between the three levels of driving activity are highlighted

\section{Keywords}

Electric vehicle; driver behaviour; road safety; intelligent transport systems; behavioural adaptation; human factors.

\section{Introduction}

New international roadmaps for reducing $\mathrm{CO}_{2}$ emissions are being accompanied by substantial financial investment in the development of sustainable transport. A large amount of funding has been allocated by private investors and governments to finance the development of renewable energy and multimodal transport systems that are energy-efficient and use cleaner fuels (United Nations, 2012; MDB Working group on Sustainable Transport, 2015). In this context, the electric vehicle (EV) is a relevant mode of transport: it is a practical alternative to conventionally fueled vehicles if the production of electricity used is not polluting. This has resulted in the provision of government 
incentives ( Valls, Royal, Sapin, Macron, \& Eckert, 2014) to make the purchase of EVs more attractive (e.g., in France in 2015 a 6300 euros bonus increasing to 10000 euros if associated with the destruction of an old diesel vehicle; against a 5000 euros bonus in 2011), and an increasingly varying range of EV models being offered by manufacturers to meet the specific needs of users, for both private and fleet vehicles (vehicles with 2 or 5 seats, varying range, etc).

Electric vehicles have specific properties, however, that are novel for drivers of conventionally fuelled vehicles. Drivers have to pay attention to the impact of the absence of vehicle noise at low speed (Cocron and Krems, 2013; Sandberg, Goubert, \& Mioduszewski, 2010). They have to master the regenerative braking function that uses deceleration to charge the vehicle (Cocron et al., 2013). Drivers have also to deal with the limited range of the car and to plan for the charging of the electric batteries (Franke, Neumann, Bühler, Cocron, \& Krems, 2012). Moreover, previous research shows that people are not yet used to managing electricity in the vehicle. They lack knowledge about electricity and batteries, and that affects their understanding of the EV and the best way to interact with it (Caperello \& Kurani, 2012; Cocron et al. 2011; Strömberg, Andersson, Almgren, Ericsson, Karlsson, \& Nåbo, 2011). Given these issues, and for the successful deployment of EVs, it is important to understand to what extent driving activity is modified by the specific features of the EV: that is, what behaviours arise in order to interact with it efficiently from an economical and safe point of view. We review briefly below relevant research findings in this area.

\subsection{Driving tasks}

The model of the driving task proposed by Michon (Michon, 1978, 1985; see also Van der Molen \& Bötticher, 1988) provides an efficient framework for describing the specific driving activity engaged in by drivers during daily use of the EV. Michon modeled driving as a hierarchical categorization of all the tasks the driver must make throughout a trip. The model is useful in classifying new tasks that derive from the use of $\mathrm{EV}$ technology and changes to existing tasks, as well as the behaviours implemented to manage them. 
In Michon's model $(1978,1985)$, three main levels of tasks are differentiated. At the strategic level the tasks performed relate to trip planning. Decisions concern the choice of a relevant route to reach a destination according to constraints such as the time the driver has, the amount of time allocated to the trip, the choice of the vehicle; and so on. Here, the driver might evaluate the most comfortable and quickest route (based on roadwork, traffic jams, etc), and any potentially dangerous situations (driving at night, driving in rain) (Wilde, 1982; Wilde, Gerszke, \& Paulozza, 1998). There is the possibility at the strategic level that driving an electric car will change the way trips are planned because of its limited range. In current generation EVs, range is very restricted compared to that of a conventionally fuelled vehicle and energy becomes a daily factor to manage, as trips are limited in terms of distance. New strategic tasks are thus generated: drivers will have to take greater account of their travel itineraries, of unforeseen events, of the location of charge stations, and so on. The few studies that have explored feedback from long-term EV users confirm that daily use leads to the emergence of new behaviours. This is not immediate and requires a learning process, during which drivers understand how the EV range fits into their lifestyle, and adapt their trip planning accordingly. Generally, it seems that drivers modify their driving behaviours, such as speed and trip routes, adopt safe driving strategies to avoid critical range situations (Franke et al., 2012; Pichelmann, Franke, \& Krems, 2013; Rolim, Gonçalves, Farias, \& Rodrigues, 2012; Woodjack, Garas, Lentz, Turrentine, Tal, \& Nicholas, 2012) and develop a charging routine (Bunce, Harris, \& Burgess, 2014). Finally, the strategic level is modified for some drivers by the emergence of more trips done with the EV (Rolim et al., 2012). Thus, there is evidence that daily use of an EV brings about some new driving behaviours at the strategic level of driving.

Michon's model includes other driving tasks distributed across two additional levels that can also be modified by the management of the specific features of the EV. At the tactical level, the driver must analyze in real time modifications to the traffic environment and adapt actual driving behaviours and his/her interactions with other road users according to circumstances; the driver must plan actions under specific situational contexts. When driving an electric car, task activity at this level would be amplified by the need to pay more attention to interactions with pedestrians. In France, for example, 
pedestrians are not accustomed to interacting with silent vehicles: there are still few electric cars on the road (only 42000 EVs were registered in France between 2011 and 2014; cf. AVERE France, 2015), and bicycles make up only $2.6 \%$ of all trips made by the French (according to the last national study on French mobility, Revue du CGDD, 2010). Because people detect several operating conditions of cars by visual and auditory cues, the lack of noise at low speeds could create new safety issues. Experiments show that the time from the first detection of a target vehicle to the instant the vehicle passes the pedestrian location is significantly decreased with an EV (Czuka, Conter, \& Wehr, 2014; Garay-Vega, Hastings, Pollard, Zuschlag, \& Stearns, 2010), which impacts on the ability of pedestrians to travel safely. Driving EVs at the tactical level will therefore have to take account of the silent nature of the $\mathrm{EV}$, obliging the driver to adopt more attentive behaviours to other road users.

Finally, the most basic level of Michon's $(1978,1985)$ model of driving is the operational level, which relates to control of the stability of the vehicle (control of the brake and accelerator, lateral control, and so on). In driving an electric car, users in France will have to get used to driving with only accelerator and brake pedals: in France, the percentage of automatic vehicles in the vehicle fleet, with only two pedals, is marginal; manual transmission vehicles are the norm (in 2014 automatic vehicles represented less than $15 \%$ of the cars sold; cf. Comité des Constructeurs Français d'Automobiles, 2014). The presence of a feature absent in conventional cars - regenerative brakingadds an additional task at the operational level of driving: in some vehicles the car brakes when the driver releases pressure on the accelerator pedal (Vilimek et al., 2012) to enable a certain amount of kinetic energy to be recovered and transferred to the battery. This new control mechanism, regenerative braking, offers new opportunities for energy management behaviour compared to conventional cars. However, it may impact on the operational activities of the driver who needs time to become familiarized with its operation (Cocran et al., 2013).

\subsection{Objectives and Context of the study}

The aim of the study presented in this paper is to describe the specific behaviours engaged in by 
drivers during prolonged daily use of an EV and, more generally, the driving activity that emerges. Like the few studies that have examined how drivers deal with the limited range of the EV and have highlighted the emergence of new adaptive behaviours, we postulate, by extension, that new behaviours arise at each of the levels of driving activity described above to take over the specific properties of the EV. Our hypotheses are as follows:

- We anticipate that adaptive driving behaviours will need time to arise at all driving levels; that is, will require an accumulation of experience to emerge.

- Concerning the limited range of the EV, we hypothesize that drivers not accustomed to managing energy daily (usually, s/he refuels after several weeks) will develop strategies in order to maximize the distances they can travel with the car, and identify better ways to charge the vehicle through successful experiences. Overall, they will progressively follow some new habits in planning their trips at the strategic level of driving.

- With respect to the EV silent feature, we hypothesize that more or less risky situations could occur and that drivers will adapt their driving behaviours at the tactical level to compensate for the lack of noise.

- Finally, regarding regenerative braking, we hypothesize that the repetition of similar experiences will allow the driver to acquire an optimal driving style by mastering the feature, which will modify driving behaviour at the operational level of driving.

In order to explore the hypotheses above, the study presented in this paper was designed as a longitudinal, self-reported, evaluation of driving changes in the context of daily use of an EV over a period of six months. A study already conducted in Germany (Cocron, Bühler, Franke, Neumann, \& Krems, 2011; Cocron et al. 2011), the USA (Woodjack et al., 2012) and England (Everett, Walsh, Smith, Burgess, \& Harris, 2010) - for the auto manufacturer Bavarian Motor Works (BMW) - was replicated in Paris (see also Vilimek et al., 2012). It focused on the acceptance, and new driving behaviours, of users of the EV. In this paper, deriving from the French study, only the latter aspect is considered. 


\section{Method}

\subsection{Electric vehicles}

The study was part of the MINI E France Project, led by The French Institute of Science and Technology for Transport, Development and Networks (IFSTTAR), and carried out under contract for BMW Germany. Twenty-five MINI E conversion electric vehicles, similar in external appearance to the MINI Cooper, but with only two seats and equipped with a lithium-ion battery, were utilized in the study. In everyday life, in real conditions and depending on the driving style, the average range of the MINI E is roughly $160 \mathrm{~km}$ (100 miles).

All the MINI E vehicles have regenerative braking, a unique function integrated in most EVs. This technology allows for the recapturing of energy otherwise lost or unutilized during braking, coasting, or downhill driving; while, at the same time, slowing the vehicle. Regenerative braking in the MINI E is integrated with the accelerator pedal, effectively allowing the driver to drive the car with one pedal; the car brakes when the driver releases pressure on the accelerator pedal (Vilimek et al., 2012). The vehicle has also a conventional brake pedal. To charge the vehicle, each participant had a wall box of 12 amps installed in his or her home by the French electricity provider EDF (Electricité de France). Drivers could also charge their vehicles from public charging stations located around Paris (at 27 public stations in the outer suburbs of the Paris area and 84 in Paris). A full charge took about 9 hours to complete.

\subsection{Procedure and material}

Data were collected from several questionnaires, from travel and charge diaries, and from focus groups. To assess changes in behaviour and acceptability occurring over time with use of the EV, data 
were collected across three time intervals: at T0 month, T3 months and at T6 months. The data collection tool set was designed originally by the German research team that worked on the first MINI E study (Bühler, Neumann, Cocron, Franke, \& Krems, 2011; Franke, Bühler, Cocron, Neumann, \& Krems, 2012; Franke \& Krems, 2013ª Franke \& Krems, 2013º Krems, Franke, Neumann, \& Cocron, 2010).

\subsubsection{Questionnaires}

Two questionnaires were administered during a face-to-face interview at the beginning of the study (T0 month), before and after a short test drive of the MINI E. During the test drive each participant, accompanied by the interviewer, drove the MINI E for 30 minutes around the BMW Velizy car dealership in Paris. The first questionnaire addressed the prospective views and expectations of future users about the electric vehicle, their considerations about the ecological and technical aspects of EVs and also their driving habits with a traditional car. The second questionnaire contained items relating to their impression of the MINI E driving experience and properties.

After 3 months of use of the electric car (T3 months), participants were asked to complete two questionnaires on the Internet, containing items that were either existing items from T0 month, or new items. The new ones related to the experience and perceptions of participants about the use of the MINI E on a daily basis. Several topics were covered: the drive, charge, displays inside the car, the absence of noise of the vehicle, regenerative braking, and critical situations encountered. Finally, after 6 months (T6 months), participants again completed a questionnaire during a face-to-face meeting, in which the majority of items were identical to items from previous questionnaires. This long delay allowed us to consider the responses as being no longer the result of attraction to the novelty of the vehicle per se but, probably, as the reflection of the implementation of sustainable behaviours that persisted over time.

\subsubsection{Travel Patterns}

During the study, participants also completed travel and charge diaries, each for a period spanning one week. At T0 month, before they used the EV, they had to register in a travel diary all their trips, 
detailing the trip distance, means of transport taken, the purpose of the trip, and departure and arrival times for their own conventional car. At T3 and T6 months, they completed travel diaries pertaining to all of their trips, including those with the MINI E. Users were also required to complete charge diaries detailing all battery charges that they made during a one-week period. Here, users reported on the following characteristics: place of charge, charge status at the beginning and the end of the charging process, and the reasons for the charge. Obviously, daily record keeping was desirable, but the rhythm of life of participants would not allow them to be truly exhaustive in their note taking for the entire duration of the study. So, to ensure that they recorded information accurately, it was expected that each diary should be completed for one week only. This short period of data collection yielded highquality data, since the exercise wasn't constraining.

\subsection{Participants}

More than 900 people applied online to participate in this study. Applicants were invited to provide information about relevant aspects of their socio-demographic and psychographic background and were asked to indicate whether they would actually be able to use the MINI E on a regular basis, and to pay a monthly leasing fee of typically about 475 euros per month, including insurance (see Vilimek et al., 2012).

Fifty subjects were chosen based on the number of kilometers they were driving each day. The aim was to recruit drivers who would drive often enough to experience the vehicle and adapt to its novel features. They were also chosen on the basis that they lived in the Paris area, had a garage or a dedicated parking place for the car, and had access to suitable electrical power and other technical apparatus needed to drive the vehicle. Finally, the selection procedure was aimed at ensuring a minimum number of women were included in the sample and to have a majority of drivers who had had no experience with electric or hybrid vehicles.

For this paper, data for only 36 participants were analyzed because of difficulties associated with the long (6-months) duration of the study: some subjects dropped out of the study and others did not 
respond to all of the administered questionnaires. Overall, the sample comprised six women and thirty men, with an average age of 44.1 years $(\mathrm{SD}=7.98)$. Of these, $27.8 \%$ were driving more than $70 \mathrm{~km}$ per day, 30.6\% had already owned a conventional MINI vehicle, $25 \%$ had experienced an electric vehicle and $19.4 \%$ had experienced a hybrid vehicle. All participants had at least one car at home; and $75 \%$ at least two. Whilst the MINI E is only a two-seat car, all participants were allowed during the study to use their own, private, vehicle(s) to carry additional passengers, or for long trips that exceeded the range of the MINI E.

\section{Results}

In order to study the changes reported by participants in behaviour that occurred after a long period of use of EVs, we analyze in this paper results from the post test-drive questionnaire (at T0 month, after 30 minutes of use), and from the final questionnaire (at T6 months, after 6 months of use). Moreover, the travel diaries at T0 month and T6 months are compared, and the charge diary at T6 months is examined.

The results are derived from the quantitative analysis of Likert scales and diaries. The questionnaires contained items measured on a Likert scale of six points, ranging from 1 "very strongly disagree" to 6 "very strongly agree". Other items, involving ranking by preference, also needed to be completed.

In Annex 1 we present for each six points of the Likert scale item the number and percentage of participants who responded, respectively. We also indicate the percentage of "agreement" answers that result from the aggregation of the top three values for the six points of the Likert scale (answers 4-56). To test whether the "agreement" percentage is significantly in the majority or minority, a one sample z-test for proportions was used to compare this value to 50\%. For that we used a one-sample ztest for proportions. The percentage of agreement, margin of error and significance values derived from the z-test are detailed in Annex 1. The items with a significant result are indicated by an asterisk. Missing values on the Likert scales questions analyzed in this paper were under $1 \%$. Concerning the diaries, only 28 participants (78\%) filled out both the travel diaries at T0 month and T6 months. The 
results were performed only on 26 participants, as data for two participants had to be filtered: one because her professional activity was very different on the two weeks studied (she is a nurse), the other because the MINI E was under repair for 5 days during the last period concerned. For these 26 participants, 24 filled in the charge diary at T6 months. Finally, in order to analyze the travel diaries and compare proportions performed for the T0 and T6 periods, we used Chi-Square tests. The output for this paper was generated using SAS/STAT software, Version 9 of the SAS System for Windows.

\subsection{EV: easy handling but inducing new tasks while driving}

The results at T0 month show, after the MINI E first test drive, that most participants consider its handling relatively easy: more than $90 \%$ of them think it is easy to use and to learn to use this vehicle (Items $\left.1^{*}, 2^{*}\right)$. However, it must not be forgotten that $25 \%$ of participants had experienced an electric vehicle before the study, making this first experience with the MINI E even easier for them. Even though a majority of the participants considered driving to be easy, we note that $22 \%$ of participants consider the amount of mental workload required to drive the MINI E greater than that for a conventional car (Item $3^{*}$ ), and that learning to use the MINI E reportedly distracted them from normal driving activities (Item $4^{*}$ ).

The results also show that most participants need time to master the electric vehicle features. Sixty seven percent of participants expect (Item 5) that, while driving, they will often be concerned about the driving range. This result is confirmed by the T6 months result which shows that $50 \%$ of participants also reported that they deliberately tried to exhaust the range several times in order to see how far they could go with the MINI E (Item 6).

Concerning the silent properties of the EV, the first test of 30 minutes revealed that nearly $90 \%$ of participants (Items $7^{*}, 8^{*}$ ) are reportedly aware that they will have to be particularly attentive to pedestrians and cyclists due to the low engine noise of the MINI E. Finally, regarding the regenerative braking, $100 \%$ of participants are confident in the fact they will very quickly get used to this new feature (Item $9 *$ ), while bearing in mind that their driving style will change as a result of using the 
regenerative braking system (94\%) (Item 10*).

Concerning our first hypothesis, all of these results confirm that optimizing the use of the electric vehicle is not immediate, and requires more than one experience with the vehicle to manage all specific particularities of the electric driving activity, despite a reported relatively easy handling.

The analysis of the results obtained at the end of the study, namely after 6 months of daily use of the $\mathrm{EV}$, allows us to explore in detail the new driving behaviours that are established in order to master this electric driving activity. These results are presented in the following sections.

\subsection{Integration of the range limitation into trip planning}

\subsubsection{Drivers are not accustomed to managing energy daily}

After 6 months of use, $78 \%$ of participants reported they had to get used to the handling of the limited range for planning of trips (Item $11^{*}$ ). However, the time needed to get used to the restricted range and charging issues of the car required a maximum of a few weeks: for $44 \%$ of participants the habituation required on average 2 weeks; for $31 \%$ of participants 4 days; for $14 \%$ of them 2 hours; and, for $11 \%$ of participants, habituation was reportedly immediate (participants completed the Item "Getting used to the MINI E as means of transport -i.e. restricted range, charging- took me ... week, days, hours")..

\subsubsection{Strategies development}

Regarding the establishment of strategies in order to manage the range limitation, $47 \%$ of the drivers reportedly took trips which allowed them to use less energy (Item 12). Concerning the charging process, one can observe the development of habits confirmed by $72 \%$ of users, who declared at the end of the study that charging the MINI E became a daily routine (Item 13*). In more detail, analysis of charge diaries shows that participants charged their vehicle on average 4.9 times per week (the average is derived from the aggregated values of each participant), mainly at night in $67 \%$ of cases, and at home in $79 \%$ of cases. On this last point, we can note that most drivers (94\%) appreciated being able to charge their MINI E at home and therefore no longer needing to go to the gas station (Item $14^{*}$ ). These data are consistent with previous findings which depict similar management strategies by 
the development of additional adaptations (Woodjack et al., 2012), and everyday routines (Franke \& Krems, 2013하 Franke, Neumann et al., 2012; Bunce et al., 2014).

\subsubsection{Emergence of new planning behaviours}

Finally, the results presented below highlight the emergence of new planning behaviours at the strategic level of the EV driving. Here, analysis of travel diaries reveals that the number of trips involving a car significantly increases between T0 month and T6 months: from $81 \%$ ( $\mathrm{ME}=+/-2.9 \%$ ) at $\mathrm{T} 0$ month to $90 \%(\mathrm{ME}=+/-2.3 \%), X^{2}(1, \mathrm{~N}=1331)=23.27, p<.0001$, at $\mathrm{T} 6$ months. These data are consistent with those reported by Rolim and colleagues (2012), who found that one third of their participants considered after 5 months of EV use that they made more trips (see also Woodjack et al., 2012).

In more detail, $84 \%(\mathrm{ME}=+/-11.9 \%)$ of trips are made by participants with the MINI E and $16 \%$ $(\mathrm{ME}=+/-11.9 \%)$ with their own car at $\mathrm{T} 6$ months of the study. Focusing on the reasons why participants have chosen their own car instead of the MINI E, participants mention the capacity of the EV (number of passengers or storage) for $67 \%$ of the 91 trips $(\mathrm{ME}=+/-9.7 \%)$ and the limited charge of the MINI E for $32 \%$ of the trips $(\mathrm{ME}=+/-9.6 \%)$.

To analyze the impact of the MINI E on mobility, we chose to restrict the sample on trips that could have be done by a MINI $\mathrm{E}$ in the two periods; that is, trips involving a car with 0 or 1 passenger. An interesting difference appears for small distances. The proportion of trips less than $5 \mathrm{~km}$ is significantly more important at $\mathrm{T} 6$ months than at T0 month: 56\% (ME $=+/-4.4 \%$ ) against $44 \%$ (ME $=+/-4.4 \%), \mathrm{X}^{2}(1, \mathrm{~N}=968), \mathrm{p}<.05$.

Moreover, $67 \%$ of drivers declared in questionnaires that they used the MINI E more than their traditional car for short trips (Item 15) and a third of users declared that they had used the MINI E for trips they usually did by foot (or by bike) before the study (Item 16). When we observe the proportion of trips done partially or completely by foot or bike indicated in the travel diaries, we obtain $19 \%$ (ME $=+/-2.9 \%)$ at $\mathrm{T} 0$ month against $12 \%(\mathrm{ME}=+/-2.4 \%)$ at $\mathrm{T} 6$ months. The difference is significant $\left(X^{2}\right.$ $(1, \mathrm{~N}=1331)=11, p<.001$. 
This increase in small trips with use of the EV might be explained by the ecological nature of the electric car. When participants were asked to evaluate the major advantages of the electric vehicles (Annex 2), the environmental point of view (the fewer localized carbon emissions while driving and the fewer carbon emissions in general if the electricity is produced by renewable energy) was the main reason chosen, which removes any guilt of participants in using more frequently their electric vehicle. Of course, it is also possible that the increase in use of the EV is due to the novelty of the vehicle and the impact of the monthly fixed payment schedule or the cheap charging process (around 1 euro for $100 \mathrm{~km}$, against 5 euros with a fueled vehicle). However, the analysis of the data between T3 months and T6 months shows that the number of trips involving only the car was relatively similar between $\mathrm{T} 3$ months $(94 \%, \mathrm{ME}=+/-1.9 \%)$ and $\mathrm{T} 6$ months $(90 \%, \mathrm{ME}=+/-2.3 \%)$. Thus, the initial enthusiasm can't explain by itself the increased use of the car in the long-term.

According to our second hypothesis relating to range management, , these results confirm that limited range involves re-definition of routes, development of a strategy for planning charges, and reconsideration of choice of using different modes of current transport. All of these adapted behaviours occur in a period of a few days or weeks and seem to result from the daily use of the EV. This idea is supported by the Woodjack et al. (2012) study which develops the notion of a lifestyle learning process and suggests that drivers learn about the unique attributes of an electric vehicle and incorporate these discoveries into their lifestyles, or "routinized practices".

\subsection{Dealing with the EV silent features}

As noted in the introduction, another important property of the EV is its silent feature. At low speed (around $30 \mathrm{~km} / \mathrm{h}$ ), unlike a conventional vehicle, EVs emit no engine noise and their approach may not be perceived by pedestrians (by contrast, beyond $20-30 \mathrm{~km} / \mathrm{h}$, the rolling noise of the vehicle on the road is more and more dominant and other users more easilyhear it approaching; see Czuka et al., 2014).

The data from the present study show that at T6 months, $58 \%$ of participants considered the MINI E 
difficult for others to hear (item 17); and, more precisely, $28 \%$ say that occasionally they weren't noticed, or were noticed late, by pedestrians (and $11 \%$ say that they were frequently not noticed by cyclists). In response to a question about situations where road users didn't hear the EV driver (Annex 3), participants confirmed that these risky situations relating to the acoustic properties of the MINI E took place at less than $30 \mathrm{~km} / \mathrm{h}$, occurred primarily in parking areas where pedestrians did not perceive that the car had started (drivers had to honk the horn to warn them), or occurred in underground garages, on driveways, and during snowy days ("when pedestrians only looked at their feet and were therefore less aware of cars").

Finally, half of all users think the lack of noise of the MINI E is potentially dangerous (item 18), which could explain why $58 \%$ of them declared that they had to get used to it (item 19), and 39\% of users reported that they had to change their driving behaviour due to this silent feature (item 20). Even if they have to pay more attention to pedestrians and drive differently, the absence of noise is perceived as an advantage for drivers (on a scale of 1 - no advantage - to 100 - major advantage drivers reported a score of 77.3 , on average; $\mathrm{SD}=21.45$ ). Seventy eight percent do not want outside vehicle noise, even though the provision of artificial noise could strengthen the perception of lowspeed vehicles for other road users, especially pedestrians (item $21 *$ ).

To conclude, the lack of noise at low speed seems to imply a change in the interaction between EV drivers and other road users, since usually their perception of the traffic environment is based on information from both the visual and auditory modalities. Because pedestrians can't hear the EV, they are more vulnerable and the EV drivers need to pay more attention. As we proposed in our hypotheses, drivers adapt their driving behaviours at the tactical level to compensate for the lack of noise.

\subsection{Saving and regenerating electric energy while driving}

The regenerative braking function in the EV offers new possibilities in addition to the different driving maneuvers possible in conventional cars. The analysis of the data confirms that new driving operational behaviours are quickly acquired in relation to this particular feature. Indeed, for $89 \%$ of 
users their driving style changed as a result of using the regenerative braking function in the MINI E (Item $22 *$ ). The consequence is that, more generally, half of them think that with their MINI E they drove in a more flexible way than with a conventionally fueled car (Item 23), and 19\% of participants report that the MINI E made them safer drivers when they drove it (Item 24*). These participants declared that they anticipated more their braking distances and tried to drive more softly, therefore inducing a more energy-efficient driving style. Thus, the regenerative braking function not only allowed drivers to regenerate electric energy while driving, but it also led some participants to adopt driving behaviours more suitable for limited range since they used it to save energy.

Another important point highlighted by the data is how much participants appreciated the regenerative feature: $100 \%$ of them liked to be able to accelerate and decelerate using just one pedal (Item $25^{*}$ ), and $89 \%$ missed the deceleration by regenerative braking when they drove a conventional vehicle (Item 26*). Ninety-seven percent of participants indicated that they would like to have an energy saving system in conventional vehicles that operates like the regenerative braking system in the MINI E (Item $27 *)$.

It seems that the pleasure of, and advantages in using, regenerative braking led to a very frequent utilization of this feature, which become almost procedural. For $83 \%$ of participants, use of regenerative braking in order to avoid the use of the braking pedal was game-like (Item $28^{*}$ ), and they estimated that they used it instead of the brake pedal in $89.9 \%$ ( $\mathrm{SD}=8.51$ ) of braking situations (participants completed the Item: "For what percentage of braking situations did you use the regenerative braking instead of using the brake pedal?"). Whether this actually enhances or reduces safety in situations that require emergency braking is in important issue for further research.

The reportedly automatic control of the regenerative braking was acquired rapidly. All participants estimated that this occurred quickly (Item $29 *$ ): $58 \%$ of participants estimated that they needed 1.5 hours to use it automatically; $33 \%$ of participants estimated 3 days; for $6 \%$ of participants it was reportedly immediate; and for $3 \%$ of participants assessed it to took 4 weeks (participants completed the Item: "Adapting to the regenerative braking took me... weeks, days, hours"). Similar findings for a short adaptation phase are reported by Cocron and collaborators (2013). 
In summary, these results show that the driving experience of the MINI E leads quickly, based on the self-reported behaviours of drivers, to behavioural control of the regenerative braking function. As we proposed in our last hypothesis, this new feature alters the activity of driving in an operational way since the users only use a single pedal (i.e., the accelerator pedal) to accelerate and decelerate; it also plays a role in the implementation of strategic energy management as its use enhances energy conservation.

\section{Discussion}

\subsection{Adaptive driving behaviours arise at all driving levels}

The study described in this article has focused on driving activity related to the daily utilization of the EV; specifically, the MINI E. The advantage of this longitudinal study was to identify, from the selfreported behaviours of MINI E drivers, adapted driving behaviours that emerge after several months due to the special properties of the vehicle.

Concerning the limited range of the EV, the findings of our study are consistent with those of other longitudinal studies (Franke, Neumann et al., 2012; Pichelmann et al., 2013; Rolim et al., 2012; Woodjack et al., 2012), in showing that handling this limitation leads participants to maximize driving distances. In order to optimize range management, participants also defined from their experiences the best way to charge the MINI E to suit their lifestyle and their needs. Our findings support the charging routine described by Bunce and collaborators (2014) who concluded that drivers' charging behaviour became more "relaxed overtime as they developed knowledge and confidence in the battery range" (Bunce et al., 2014, p. 286). However, our work highlights some new self-reported habits that appear at the strategic level: participants establish new trip planning behaviours. They made more short trips and used the car more frequently during their travels. We proposed that this reorganization of trip planning might be due to the ecological properties of the EV: the electric driving activity is also 
modified by the possibility to use cleaner fuels.

Regarding other EV features, participants reported that the silent function would involve appropriate anticipated driving behaviours. They also identified typical risky situations where they were more attentive, modifying the tactical level of EV driving. These results are in the same direction as those reported by Cocron and Krems (2013) on driver perceptions of the safety implications of quiet electric vehicles. Drivers identified similar risky situations and reported that they looked out for cyclists and pedestrians to proactively prevent critical incidents. Overall, the results presented in this article confirm that, even if learning to operate the EV is relatively simple, driving efficiently seems not to be spontaneous: a period of handling would be necessary to implement more effective behaviours at all levels of the electric driving activity.

Finally, concerning the regenerative braking function, the self-reported behaviours of drivers indicate that it rapidly enriches maneuver control at the operational level of driving. The majority of participants declared to have modified their driving style and some to have driven in a more flexible way. They also declared to use the regenerative braking function very frequently (around $90 \%$ of the braking situations) and that this acquisition was very quick. Ours results are consistent with those of another longitudinal study (Cocron et al., 2013) which reported, from onboard data logger recordings, the same rapidity in learning to use the regenerative braking, and the same frequency of use.

\subsection{Adaptive driving behaviours emerge progressively: The Rasmussen Model explanation}

Each property of the MINI that is to be managed (range, silent feature, regenerative braking) does not present itself at the same frequency during the driving activity; and so, the period of handling will vary. In the Human Behaviour model of Rasmussen (1983), behaviours are distinguished according to their familiarity with the task for which they are implemented. When the situation is novel and unexpected the individual will plan his/her actions from all his/her knowledge according to the aims established. However, when similar situations occur on several occasions, the individual develops rule-based behaviours or procedures learned through successful experiences. Finally, Skill-based 
behaviours are developed through practice of repeated situations, involving primarily the automation of sensorimotor tasks.

In the case of the management of the limited range, we propose that drivers seem to develop with practice strategies which become rules and procedures over time, adopting the most appropriate behaviours to save energy: drivers take greater account of the distance of their trips; they acquire daily charge processes; and they reconsider their choice of using different modes of current transport. These rules and procedures can explain why, at the end of the study, more than half of participants (58\%) perceived the range as less constraining than they thought it would be at the beginning of the study (Item 19).

Concerning the accumulation of risky silent situations due to the fact that the pedestrian does not hear the car coming (in parking lots or garages, or on snowy days), the Human Behaviour model of Rasmussen leads us to propose that electric vehicle drivers progressively identify rules to follow which change their driving behaviour to overcome pedestrian conflicts. Drivers are confident to the point that they prefer to enhance their attention and identify these rules and procedures with practice, rather than to add artificial external noise on the car.

Finally, regarding the regenerative braking, EV users declared a very frequent use: according to them, around $90 \%$ of the braking situations were supported by this function. So, through daily use of it, the driving experience seems to lead quickly to acquisition of procedural skills; that is, an automatic control of the regenerative braking. This would have the effect that participants modify their driving style to obtain the most appropriate behaviours to save energy while driving in order to guarantee the range of the vehicle.

Globally, as was expected, behaviour modifications emerged progressively at all driving activity levels (Michon, 1978, 1985) in order to optimize daily mobility and to make EV use safer. Behaviours arise in the driving activity of $\mathrm{EV}$, and transform it as driving skills and rules are acquired over time. 


\subsection{Proposition of a Transversal Modulation}

An interesting finding revealed by our study is what we may term the "Transversal Modulation" that each level of the electric driving activity induces on the other levels. For example, the strategic level will benefit from the development of the driving skills at the operational level. According to the selfreported behaviours of drivers, the consequence of the regenerative braking is the implementation of strategic energy management because its use enhances energy conservation and, so, offers new strategic possibilities. Otherwise, because driving in a more flexible way allows the driver to save more energy, operational skills will also positively influence the tactical level of the EV driving by decreasing the potential for a critical event. Finally, as proposed by Rasmussen (1983), mastering driving skills allows for a reduction in mental workload and the ability to devote attention to other events: operational skills will thus allow for the allocation of more attention at the tactical level. In the same vein, tactical rules followed by the driver to increase their attention to pedestrians force them to modify their driving to anticipate pedestrian behaviours. Tactical rules influence the operational level by inducing a driving style that is more flexible. Finally, strategic rules may also influence other levels of driving activity: because the driver selects trips less costly in terms of energy, the driver decreases the operational management of the range.

In view of these transversal relationships between levels involved in the electric driving activity, the period of handling the range issue requires the driver not only to adopt effective strategic behaviours, but also skills and rules at the other driving levels. Our participants declared that they got used to the restricted range and charging issues of the car in a maximum of two weeks. But, in reality, the time required should be longer for optimal management: our results show that driving at the strategic level would be optimized by behaviours which emerge from the management of the other levels. In the experiment of Pichelmann and collaborators (2013), the authors concluded (via a data logger which recorded the maximum available range of EV drivers during daily use), that a person needs approximately three months to complete adaptation to EV range. The difference between their result and the self-reports of our participants shows that several factors are at work to optimize range management, and one could conclude that the emergence of effective range optimization behaviours 
continues for a long period of use, well after the time at which the driver thinks s/he has mastered the range issue.

Finally, we acknowledge that this study has some limitations. The sample of participants is not representative of the whole population, but rather of potential early adopters of EV s (exemplified by their previous experience of electric or hybrid vehicles). Hence, the findings are not truly representative of the French population at large. Furthermore, the study is a self-reported assessment of driving changes provided by participants of the study; and, hence, it is possible that there may be some discrepancies between self-reported and actual behaviours. Nevertheless, the findings of the study improve further our understanding of driver adaptation to electric vehicles.

\section{Conclusions}

The findings from this study are generally consistent with previous research that has described how EV users deal with range and mobility during daily use of this kind of vehicle. However, our study goes further by categorising new behaviours that arise at each of the levels of the driving activity (strategic, tactical and operational) and by proposing the Transversal Modulation that each level of electric driving activity seems to induce on other levels.

The aim of the next phase of our research program will be to design and develop training aids for drivers of the electric car, which highlight and accelerate the acquisition of the rules and EV skills that optimize the efficiency and safety of EV driving. This training assistance would detail the ideal behaviours to have in order to drive in an eco-driving manner, thereby helping to reduce drivers' concerns related to limited range, optimise safety, and provide a basis for the more widespread uptake of EV's within the general vehicle fleet.

\section{Acknowledgements}


We are grateful to BMW Germany and BMW France for providing us with the opportunity to conduct this study. In particular, we thank Michaela Luehr, Roman Vilimek, Michael Hajesch, Maximillian Schwalm and Jean-Michel Cavret and his colleagues for their support, and for their input to the project. We thank colleagues from CEESAR, for their important role in recruiting participants and collecting the data for this study; in particular, Julien Adrian, Annie Langlois and Reakka Krishnakumar. We also thank Julien Delaitre, Magalie Pierre (EDF) and Julien Augerat (Veolia) for their support. Finally, we want to thank the two reviewers of the article for their insightful and constructive comments.

\section{References}

AVERE France, Baromètre mensuel (Janvier 2015). Baromètre mensuel AVERE-France Marché automobile: véhicules électriques et hybrides (Accessed online 13.08.2015). Available at:http://www.avere-

france.org/Uploads/Documents/142072941061e9c06ea9a85a5088a499df6458d276-

Barom\%C3\%A8tre\%20bilan\%202014.pdf

Bunce, L., Harris, M., \& Burgess, M. (2014). Charge up then charge out? Drivers' perceptions and experiences of electric vehicles in the UK. Transportation Research Part A, 59, 278-287.

Bühler, F., Neumann, I., Cocron, P., Franke, T., \& Krems, J. F. (2011). Usage patterns of electric vehicles: A reliable indicator of acceptance? Findings from a German field study. In Proceedings of the 90th Annual Meeting of the Transportation Research Board.

Caperello, N. D., \& Kurani, K. S. (2012). Households' Stories of Their Encounters With a Plug-In Hybrid Electric Vehicle. Environment and Behavior, 44(4), 493-508.

Cocron, P., Bühler, F., Franke, T., Neumann, I, Dielmann, B, \& Krems, J. F. (2013). Energy recapture through deceleration - regenerative braking in electric vehicles from a user perspective, Ergonomics, 56(8), 1203-15. 
Cocron, P., Bühler, F., Franke, T., Neumann, I., \& Krems., J.F. (2011). The silence of electric vehicles - blessing or curse? In: Proceedings of the 90th Annual Meeting of the Transportation Research Board. Washington, D.C., January 2011.

Cocron, P., Bühler, F., Neumann, I., Franke, T., Krems, J.F., Schwalm, M., \& Keinath, A. (2011). Methods of evaluating electric vehicles from a user's perspective - the MINI E field trial in Berlin. IET Intelligent Transport Systems, 5(2), 127-133.

Cocron, P., \& Krems, J.F. (2013). Driver perceptions of the safety implications of quiet electric vehicles. Accident Analysis and Prevention, 58, 122- 131.

Comité des Constructeurs Français d'Automobiles, CCFA, 2014. Tableau de bord automobile, $1^{\text {er }}$ semestre 2014, n³8. (Accessed online 11.08.15). Available at: http://www.ccfa.fr/IMG/pdf/tdb38$\underline{1 \text { trim2014.pdf }}$

Czuka, M., Conter, M., \& Wehr, R. (2014). Drivekustik: acoustic detectability of electric vehicles. Proceedings of $6^{\text {th }}$ Congress of Alps-Adria Acoustics Association, Graz, Austria.

Davies, J., \& Kurani, K. S. (2010). Households' Plug-in Hybrid Electric Vehicle Recharging Behavior: 1 Observed variation in households' use of a 5kWh blended PHEV-conversion, TRB Annual Meeting CD-ROM, 10-1802.

Everett, A., Walsh, C., Smith, K., Burgess, M. \& Harris, M. (2010). Ultra Low Carbon Vehicle. Demonstrator Programme. In: EVS 25. Proceedings of the 25th World Battery, Hybrid and Fuel Cell Electric Vehicle Symposium \& Exhibition. Shenzhen, China.

Franke, T., Bühler, F., Cocron, P., Neumann, I., \& Krems, J.F. (2012). Enhancing sustainability of electric vehicles: A field study approach to understanding user acceptance and behavior. In Sullman, M., Dorn. L. (Eds.). Advances in Traffic Psychology (p. 295-306). Farnham, UK: Ashgate.

Franke, T., \& Krems, J.F. (2013a). What drives range preferences in electric vehicle users? Transportation Policy, 30, 56-62. 
Franke, T., \& Krems, J.F. (2013b). Interacting with limited mobility resources: Psychological range levels in electric vehicle use. Transportation Research Part A: Policy and Practice, 48, 109122.

Franke, T., \& Krems, J.F. (2013c). Understanding charging behavior of electric vehicle users (2013). Transportation Research Part F, 21, 75-89.

Franke, T., Neumann, I., Bühler, F., Cocron, P., \& Krems, J.F. (2012). Experiencing Range in an Electric Vehicle: Understanding Psychological Barriers. Applied Psychology: An International review, 61(3), 368-391.

Garay-Vega, L., Hastings, A., Pollard, J. K., Zuschlag, M., \& Stearns M.D. (2010). Quieter Cars and the Safety of Blind Pedestrians: Phase I., DOT HS 811 304, April 2010.

Golob, J., \& Gould, T.F. (1998). Projecting use of electric vehicles from household vehicle trials, Transportation Research B: Methodology, 32(7), pp. 441-454.

Krems, J. F., Franke, T. Neumann, I., \& Cocron, P. (2010). Research methods to assess the acceptance of EVs - experiences from an EV user study. In: Smart Systems Integration, ed. T. Gessner. Proceedings of the 4th European Conference \& Exhibition on Integration Issues of Miniaturized Systems. Como, Italy: VDE Verlag.

MDB Working group on Sustainable Transport progress report, 2015. Progress Report (2013-2014) of the MDB Working Group on Sustainable Transport. (Accessed online 11.08.15). Available at: https://sustainabledevelopment.un.org/index.php?page=view\&type=400\&nr=1764\&menu=35

Michon, J. A. (1978). Dealing with danger. Technical Report of the European Commission MRC Workshop on physiological and psychological factors in performance under hazardous conditions with Special Reference to Road traffic Accidents. Gieten, The Netherlands, 23-25 May, 1978. Haren (The Netherlands): Traffic Research Center, University of Groningen, Report VK 79-01.

Michon, J. A. (1985). A critical view of driver behavior models: What do we know, what should we do? In L. Evans \& R. C. Schwing (Eds.), Human behavior and traffic safety (pp. 485-520). Plenum press, New York. 
Pichelmann, S., Franke, T., \& Krems, J. (2013). The timeframe of Adaptation to Electric Vehicle Range. M. Kurosu (Ed.): Human-Computer Interaction, Part II, HCII 2013, LNCS 8005, pp. $612-620$.

Rasmussen, J. (1983). Skills, rules and knowledge: Signals, signs and symbols, and other distinctions in human performance models. IEEE Transactions on Systems, Man, and Cybernetics, Vol. $S M C-13,3,257-266$.

Revue du CGDD, Commissariat Général au Développement Durable (2010). La mobilité des Français 2008, (Accessed online 11.08.15). Available at: http://www.developpementdurable.gouv.fr/IMG/pdf/Rev3.pdf

Rolim, C. C., Gonçalves, G. N., Farias, T. L., \& Rodrigues, O. (2012). Impact of electric vehicle adoption on driver behavior and environmental performance, Social and Behavioral Sciences, $54,706-715$.

Sandberg, U., Goubert, L., \& Mioduszewski, P. (2010). Are vehicles driven in electric mode so quiet that they need acoustic warning signals? Proceedings of $20^{\text {th }}$ International Congress on Acoustics, ICA, Sydney, Australia.

Strömberg, H., Andersson, P., Almgren, S., Ericsson, J., Karlsson, M., \& Nåbo, A. (2011). Driver Interfaces for Electric Vehicles. Proceedings of the 3rd International Conference on Automotive User Interfaces and Interactive Vehicular Applications, Salzburg, Austria, pp. 177-184.

United Nations (2012). Report of the United Nations Conference on Sustainable Development Rio de Janeiro, Brazil 20-22 June 2012. (Accessed online 11.08.15). Available at: http://www.uncsd2012.org/content/documents/814UNCSD\%20REPORT\%20final\%20revs.pdf

Valls, E., Royal, S., Sapin, M., Macron, E., \& Eckert, C. (2012). Aide à l'acquisition et à la location des véhicules peu polluants (Décret $\mathrm{n}^{\circ}$ 2014-1672). France: Ministère de l'écologie, du développement durable et de l'énergie, du 30 decembre 2014, Journal officiel de la république française, Texte 14

Van der Molen, H. H., \& Bötticher, A. M. T. (1988). A hierarchical risk model for traffic participants. Ergonomics, 31, 537-555. 
Vilimek, R., Keinath, A., \& Schwals, M. (2012). The MINI E field study - Similarities and differences in international everyday EV driving. In Stanton, N.A. (Ed.), Advances in human aspects of road and rail transport (pp. 363-372). Boca Raton, FL: Taylor \& Francis Group.

Wilde, G. J. S. (1982). The theory of risk homeostasis: implication for safety and health. Risk Analysis, 2, 209-225.

Wilde, G. J. S., Gerszke, D., \& Paulozza, L. (1998). Risk optimization training and transfer. Transportation Research Part F, 1, 77-93.

Woodjack, J., Garas, D., Lentz, A., Turrentine, T., Tal, G. \& Nicholas, M. (2012). Consumers' Perceptions and Use of Electric Vehicle Range Changes Over Time Through a Lifestyle Learning Process. Proceedings of 91th TRB Annual Meeting, Washington, January. 


\section{Annex 1}

\section{Items}

Please indicate your level of agreement with the following statements:

\section{Detailed answers}

$\begin{array}{cccccc}\text { Very } & \text { Strongly } & \text { Mostly } & \text { Mostly } & \text { Strongly } & \begin{array}{c}\text { Very } \\ \text { strongly }\end{array} \\ \text { strongly } & \text { disagree } & \text { disagree } & \text { agree } & \text { agree } & \text { agree }\end{array}$

Number \& percentage
Percentage of agreement answers

Agree

Cum

$\%$

$\&$

$\&$
$\mathrm{ME}$

\section{Easy handling but inducing new tasks while driving}

\begin{tabular}{|c|c|c|c|c|c|c|c|c|c|}
\hline $\begin{array}{l}1 \text { The MINI E is easy to use } \\
\text { TO month }\end{array}$ & $0 \%$ & $0 \%$ & $6 \%$ & $36 \%$ & $58 \%$ & $0 \%$ & $\begin{array}{l}94 \% \\
7.5\end{array}$ & 5.328 & .001 \\
\hline $\begin{array}{l}2 \text { It was easy to learn how to use the MINI E } \\
\text { TO month }\end{array}$ & 1 & $0 \%$ & 2 & 17 & $44 \%$ & $0 \%$ & $\begin{array}{l}92 \% \\
9\end{array}$ & 5.004 & .001 \\
\hline $\begin{array}{l}3 \text { The amount of mental workload required to drive the } \\
\text { MINI E is greater than that for a conventional car } \\
\text { TO month }\end{array}$ & $36 \%$ & $31 \%$ & $11 \%$ & $22 \%$ & $0 \%$ & $0 \%$ & $\begin{array}{l}22 \% \\
13.6\end{array}$ & -3.336 & .001 \\
\hline $\begin{array}{l}4 \text { Learning to use the MINI did not distract me from } \\
\text { normal driving activities } \\
\text { TO month }\end{array}$ & $0 \%$ & $8 \%$ & $14 \%$ & $44 \%$ & $33 \%$ & $0 \%$ & $\begin{array}{l}78 \% \\
13.6\end{array}$ & 3.336 & .001 \\
\hline $\begin{array}{l}5 \text { While driving I will often be concerned about the } \\
\text { driving range } \\
\text { TO month }\end{array}$ & $3 \%$ & $3 \%$ & $28 \%$ & $39 \%$ & $22 \%$ & $6 \%$ & $\begin{array}{l}67 \% \\
15.4\end{array}$ & 2.004 & .053 \\
\hline
\end{tabular}




\begin{tabular}{|c|c|c|c|c|c|c|c|c|c|}
\hline $\begin{array}{l}8 \text { Due to the low engine noise of the MINI E, I will have } \\
\text { to be particularly aware of cyclists }\end{array}$ & 1 & 0 & 3 & 4 & 14 & 14 & $89 \%$ & 4.668 & .001 \\
\hline TO month & $3 \%$ & $0 \%$ & $8 \%$ & $11 \%$ & $39 \%$ & $39 \%$ & 10.3 & & \\
\hline $\begin{array}{l}9 \text { I will get used to the regenerative braking system pretty } \\
\text { quickly }\end{array}$ & 0 & 0 & 0 & 4 & 14 & 18 & $\begin{array}{l}100 \% \\
0.000\end{array}$ & 6.000 & .001 \\
\hline T0 month & $0 \%$ & $0 \%$ & $0 \%$ & $11 \%$ & $39 \%$ & $50 \%$ & & & \\
\hline $\begin{array}{l}10 \text { My driving style will change as a result of using the } \\
\text { regenerative braking }\end{array}$ & 0 & 1 & 1 & 10 & 13 & 11 & $94 \% 7.5$ & 5.328 & .001 \\
\hline TO month & $0 \%$ & $3 \%$ & $3 \%$ & $28 \%$ & $36 \%$ & $31 \%$ & & & \\
\hline
\end{tabular}

\section{Integration of the range limitation into trip planning}

\begin{tabular}{|c|c|c|c|c|c|c|c|c|c|}
\hline $\begin{array}{l}11 \text { I had to get used to the handling of the range (planning } \\
\text { of trips etc.) } \\
\text { T6 months }\end{array}$ & $0 \%$ & $3 \%$ & $19 \%$ & $36 \%$ & $25 \%$ & $17 \%$ & $\begin{array}{l}78 \% \\
13.6\end{array}$ & 3.336 & .001 \\
\hline $\begin{array}{l}12 \text { When I can, I do trips which allow me to use less energy } \\
\text { T6 months }\end{array}$ & $22 \%$ & $14 \%$ & $17 \%$ & $31 \%$ & $8 \%$ & $8 \%$ & $47 \%$ & -0.329 & .744 \\
\hline $\begin{array}{l}13 \text { Charging the MINI E became a daily routine to me } \\
\text { T6 months }\end{array}$ & $8 \%$ & $0 \%$ & $19 \%$ & $19 \%$ & $22 \%$ & $31 \%$ & $72 \%$ & 2.664 & .05 \\
\hline $\begin{array}{l}15 \text { For short trips, I used more the MINI E than my } \\
\text { traditional car } \\
\text { T6 months }\end{array}$ & $25 \%$ & $3 \%$ & $6 \%$ & $19 \%$ & $31 \%$ & $17 \%$ & $67 \%$ & 2004 & .053 \\
\hline $\begin{array}{l}16 \text { I used the MINI E for trips I usually do by foot (or by } \\
\text { bike) before the study } \\
\text { T6 months }\end{array}$ & $39 \%$ & $11 \%$ & $17 \%$ & $25 \%$ & $8 \%$ & $0 \%$ & $\begin{array}{l}33 \% \\
15.4\end{array}$ & -2.004 & .053 \\
\hline
\end{tabular}

\section{Dealing with the EV silent features}




\begin{tabular}{|c|c|c|c|c|c|c|c|c|c|}
\hline $\begin{array}{l}17 \text { The MINI E is difficult for others to hear } \\
\text { T6 months }\end{array}$ & $6 \%$ & $8 \%$ & $28 \%$ & $47 \%$ & $3 \%$ & $8 \%$ & $\begin{array}{l}58 \% \\
16.1\end{array}$ & 0.996 & .242 \\
\hline $\begin{array}{l}18 \text { The low noise outside of the MINI E is potentially } \\
\text { dangerous } \\
\text { T6 months }\end{array}$ & $17 \%$ & $17 \%$ & $17 \%$ & $39 \%$ & $11 \%$ & $0 \%$ & $\begin{array}{l}50 \% \\
16.3\end{array}$ & 0.000 & .398 \\
\hline $\begin{array}{l}19 \text { While driving the MINI E, I mostly had to get used to } \\
\text { the lack of noise } \\
\text { T6 months }\end{array}$ & $3 \%$ & $6 \%$ & $33 \%$ & $39 \%$ & $17 \%$ & $3 \%$ & $\begin{array}{l}58 \% \\
16.1\end{array}$ & 0.996 & .242 \\
\hline $\begin{array}{l}20 \text { I had to change my driving behavior due to the lack of } \\
\text { outside noise of the MINI E } \\
\text { T6 months }\end{array}$ & $14 \%$ & $19 \%$ & 10 & $31 \%$ & $8 \%$ & $0 \%$ & $\begin{array}{l}39 \% \\
15.9\end{array}$ & -1.332 & .164 \\
\hline $\begin{array}{l}21 \text { I would not mind if my MINI E had an idle noise so that } \\
\text { others can hear me at any time (while standing, with engine } \\
\text { on) } \\
\text { T6 months }\end{array}$ & $31 \%$ & $17 \%$ & $31 \%$ & $19 \%$ & $0 \%$ & $3 \%$ & $\begin{array}{l}22 \% \\
13.6\end{array}$ & -3.336 & .001 \\
\hline
\end{tabular}

\section{Saving and regenerating electric energy while driving}

\begin{tabular}{|c|c|c|c|c|c|c|c|c|c|}
\hline $\begin{array}{l}22 \text { My driving style changed as a result of using the } \\
\text { regenerative braking function in the MINI E } \\
\text { T6 months }\end{array}$ & $3 \%$ & $0 \%$ & $8 \%$ & $36 \%$ & $31 \%$ & $22 \%$ & $\begin{array}{l}89 \% \\
10.3\end{array}$ & 4.668 & .001 \\
\hline $\begin{array}{l}23 \text { With my MINI E I drove in a more flexible way than } \\
\text { with a conventional car. } \\
\text { T6 months }\end{array}$ & $11 \%$ & $11 \%$ & $25 \%$ & $25 \%$ & $19 \%$ & $8 \%$ & $52 \%$ & 0.240 & .387 \\
\hline $\begin{array}{l}24 \text { The MINI E made me a safer driver when I drive it } \\
\text { T6 months }\end{array}$ & $14 \%$ & $11 \%$ & $56 \%$ & $11 \%$ & $6 \%$ & $3 \%$ & $19 \%$ & -3.672 & .001 \\
\hline $\begin{array}{l}26 \text { When I drive a conventional vehicle I am missing the } \\
\text { deceleration by regenerative braking } \\
\text { T6 months }\end{array}$ & $3 \%$ & $3 \%$ & $6 \%$ & $17 \%$ & $31 \%$ & $42 \%$ & $89 \%$ & 4.668 & .001 \\
\hline
\end{tabular}




\begin{tabular}{|c|c|c|c|c|c|c|c|c|c|}
\hline $\begin{array}{l}27 \text { I would like to have an energy saving system in } \\
\text { conventional vehicles that operates like the regenerative } \\
\text { braking system in the MINI E } \\
\text { T6 months }\end{array}$ & 0 & 0 & $3 \%$ & $39 \%$ & $28 \%$ & $31 \%$ & $97 \%$ & 5.664 & .001 \\
\hline $\begin{array}{l}28 \text { It has become a bit of sport or game for me using the } \\
\text { regenerative braking so that I can get to my desired position } \\
\text { without having to use the braking pedal } \\
\text { T6 months }\end{array}$ & $0 \%$ & $6 \%$ & $11 \%$ & $25 \%$ & $25 \%$ & $33 \%$ & $83 \%$ & 3.996 & .001 \\
\hline $\begin{array}{l}29 \text { I got used to the regenerative braking system pretty } \\
\text { quickly } \\
\text { T6 months }\end{array}$ & $0 \%$ & $0 \%$ & $0 \%$ & $19 \%$ & $42 \%$ & $39 \%$ & $\begin{array}{l}100 \% \\
0.000\end{array}$ & 6.000 & .001 \\
\hline
\end{tabular}

\section{Annex 2}

\section{Items}

T6 months

Degree of advantage

\section{In your opinion, what are the major advantages of electric vehicles like the MINI E?}

\section{Please indicate the degree of advantage} on a scale of 1 (no advantage) to 100 (major advantage).

\begin{tabular}{lccc}
\hline \hline Quieter inside the car & $78 \%$ & 3.36 & .001 \\
& 13.5 & 3.24 & .01 \\
Less noise outside & $77 \%$ & 13.7 & .001 \\
\hline Fewer localized carbon emissions while driving & $87 \%$ & 4.44 & \\
\hline
\end{tabular}




\begin{tabular}{|c|c|c|c|}
\hline $\begin{array}{l}\text { Fewer carbon emission in general (incl. electricity } \\
\text { generation), when charged with 'green power' (low CO2) }\end{array}$ & $68 \%$ & 2.16 & .05 \\
\hline $\begin{array}{l}\text { Fewer carbon emission in general if the electricity is } \\
\text { produced by renewable energy }\end{array}$ & $\begin{array}{l}83 \% \\
12.3\end{array}$ & 3.96 & .001 \\
\hline $\begin{array}{l}\text { Support of developing the availability of renewable } \\
\text { energies }\end{array}$ & $\begin{array}{l}69 \% \\
15.1\end{array}$ & 2.28 & .05 \\
\hline Possibility to charge during peak hours (cheap) & $\begin{array}{l}65 \% \\
15.6\end{array}$ & 1.8 & .07 \\
\hline Feeling less guilty about driving a car & $\begin{array}{l}46 \% \\
16.3\end{array}$ & -0.48 & .356 \\
\hline Fast acceleration of the vehicle & $80 \%$ & 3.6 & .01 \\
\hline Less dependence on fossil fuels such as oil & $\begin{array}{l}79 \% \\
13.3\end{array}$ & 3.48 & .001 \\
\hline $\begin{array}{l}\text { Lower costs (energy costs) than for a conventional } \\
\text { combustion engine vehicle }\end{array}$ & $\begin{array}{l}78 \% \\
13.5\end{array}$ & 3.63 & .001 \\
\hline
\end{tabular}

\section{Annex 3}

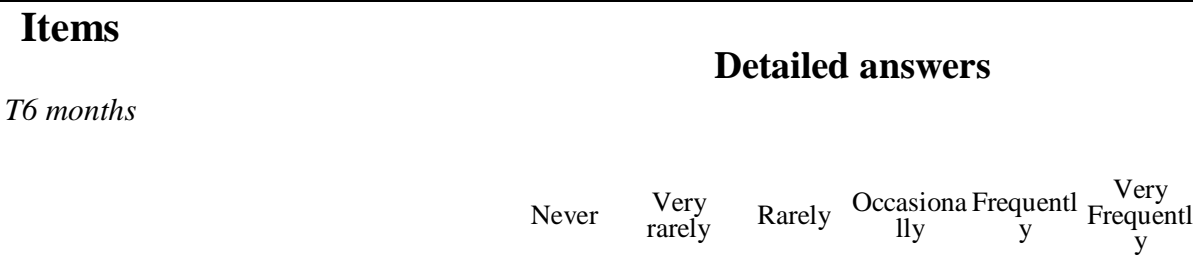

Number \& percentage
Percentage of agreement answers

Agree

Cum

$\%$

\&

ME

\section{How often did other road users not see/hear you (or see/hear you too late) in the following situations:}




\begin{tabular}{|c|c|c|c|c|c|c|c|c|c|}
\hline \multirow{3}{*}{ While starting the car. } & 18 & 7 & 3 & 6 & 0 & 2 & $22 \%$ & \multirow{3}{*}{-3.36} & \multirow{3}{*}{.001} \\
\hline & & & & & & & & & \\
\hline & $50 \%$ & $19 \%$ & $8 \%$ & $17 \%$ & $0 \%$ & $6 \%$ & 15.0 & & \\
\hline \multirow{3}{*}{ While turning the car off } & 26 & 5 & 4 & 1 & 0 & 0 & $3 \%$ & \multirow{3}{*}{-5.66} & \multirow{3}{*}{.001} \\
\hline & & & & & & & & & \\
\hline & $72 \%$ & $14 \%$ & $11 \%$ & $3 \%$ & $0 \%$ & $0 \%$ & J.4 & & \\
\hline \multirow{3}{*}{ While parking the car } & 15 & 8 & 6 & 4 & 3 & 0 & $19 \%$ & \multirow{3}{*}{-3.67} & \multirow{3}{*}{.001} \\
\hline & & & & & & & & & \\
\hline & $42 \%$ & $22 \%$ & $17 \%$ & $11 \%$ & $8 \%$ & $0 \%$ & 12.9 & & \\
\hline \multirow{3}{*}{ While driving the car $<30 \mathrm{~km} / \mathrm{h}$} & 13 & 7 & 8 & 5 & 2 & 1 & $22 \%$ & \multirow{3}{*}{-3.36} & \multirow{3}{*}{.001} \\
\hline & & & & & & & & & \\
\hline & $36 \%$ & $19 \%$ & $22 \%$ & $14 \%$ & $6 \%$ & $3 \%$ & 15.0 & & \\
\hline \multirow{3}{*}{ While driving the car in $>30 \mathrm{~km} / \mathrm{h}$} & 28 & 2 & 5 & 1 & 0 & 0 & $3 \%$ & \multirow{3}{*}{-5.66} & \multirow{3}{*}{.001} \\
\hline & & & & & & & & & \\
\hline & $78 \%$ & $6 \%$ & $14 \%$ & $3 \%$ & $0 \%$ & $0 \%$ & 5.4 & & \\
\hline \multirow{3}{*}{ In car parks } & 12 & 7 & 4 & 11 & 2 & 0 & $36 \%$ & \multirow{3}{*}{-1.66} & \multirow{3}{*}{.099} \\
\hline & & & & & & & & & \\
\hline & $33 \%$ & $19 \%$ & $11 \%$ & $31 \%$ & $6 \%$ & $0 \%$ & 10.1 & & \\
\hline \multirow{3}{*}{ By turning } & 21 & 3 & 8 & 4 & 0 & 0 & $11 \%$ & \multirow{3}{*}{-5.87} & \multirow{3}{*}{.001} \\
\hline & & & & & & & & & \\
\hline & $58 . \%$ & $8 \%$ & $22 \%$ & $11 \%$ & $0 \%$ & $0 \%$ & 10.2 & & \\
\hline
\end{tabular}

